\title{
Decrease in cuff pressure during the measurement procedure: an experimental study
}

\author{
Shota Asai ${ }^{1}$, Asuka Motoyama', Yuri Matsumoto' ${ }^{1}$ Hiroyuki Konami ${ }^{1}$, Hideaki Imanaka ${ }^{2 *}$ and Masaji Nishimura ${ }^{3}$
}

\begin{abstract}
Background: To prevent endotracheal tube (ETT)-related complications during mechanical ventilation, ETT cuff pressure should be kept within proper range. In clinical settings, cuff pressure often decreases from target values.

Methods: We performed an experimental study to investigate the effects of measuring devices and endotracheal tubes on change in cuff pressure. We continuously measured cuff pressure by inserting a three-way stopcock in the middle of an ETT pilot balloon system. After adjusting the cuff pressure to $24 \mathrm{cmH}_{2} \mathrm{O}$, we disconnected and reconnected each cuff inflator to the inflation valve of the ETT and measured the changes in the cuff pressure. We measured the change in cuff pressure with different ETT sizes, cuff shapes, brands of cuff inflator, and with and without added extension tubes.
\end{abstract}

Results: The cuff pressure decreased, on average, by $6.6 \mathrm{cmH}_{2} \mathrm{O}$ (standard deviation 1.9), when connecting the cuff inflator to the pilot balloon. The measured cuff pressure was less than $20 \mathrm{cmH}_{2} \mathrm{O}$ in $67 \%$ of the tests. The cuff pressure decreased more when an extension tube was used. The brand of cuff inflator made no difference to the pressure loss. The cuff pressure decreased more with ETTs of smaller size and with ETTs with pyriform cuffs.

Conclusions: Procedures to connect cuff inflators to inflation valves resulted in the loss of cuff pressure by 6.6 $\mathrm{CmH}_{2} \mathrm{O}$ on average.

Keywords: Cuff pressure, Endotracheal tube, Cuff inflator, Cuff shape

\section{Background}

An endotracheal tube (ETT) with a cuff is commonly used during invasive mechanical ventilation. It is recommended to maintain cuff pressure within $20-30 \mathrm{cmH}_{2} \mathrm{O}$ [1-4]. Excessive cuff pressure increases the risk of tracheal injury and stenosis, and insufficient cuff pressure can result in air leakage, aspiration, and unplanned extubation [4]. A procedure to maintain cuff pressure at appropriate range may reduce cuff leak, aspiration, and tracheal injury. Several factors are known to affect cuff pressure: ETT size, cuff size, initial cuff pressure, measuring devices, and various patient profiles [5]. Despite frequent readjustment, we failed to prevent changes in cuff pressure in critically ill patients [6], and we wondered if there might be a problem related to the measurement procedure. To test a hypothesis that the action of measuring cuff pressure contributed to the loss of pressure, we

\footnotetext{
* Correspondence: imanakah@tokushima-u.ac.jp

2Emergency and Disaster Medicine, Tokushima University Hospital,

Tokushima 770-8503, Japan

Full list of author information is available at the end of the article
}

investigated the changes in cuff pressure during the measurement procedure by using various measuring devices and tracheal tubes with different cuff shapes.

\section{Methods}

An experimental setup is demonstrated in Figure 1. For each test, we cut the ETT pilot cuff line in the middle and inserted a three-way stopcock, securely gluing the connecting surfaces around the stopcock so that no leaks were present. Intubation was simulated by placing ETTs in the sheath of a $20-\mathrm{ml}$ syringe (inner diameter, $1.9 \mathrm{~cm}$ ), because its size was similar to the human trachea (inner diameter, $2.0 \mathrm{~cm}$ ). A pressure transducer (Medex TranStar MX950, Dublin, OH, USA) was connected to the stopcock, and the cuff pressure was continuously measured with a bedside monitor (Nihon Kohden, BSM-9101, Tokyo, Japan). We connected each cuff inflator to an inflator valve of the ETT and read the value $\left(24 \mathrm{cmH}_{2} \mathrm{O}\right)$ displayed on each cuff inflator. We chose such target because pressure reading was only marked every $2 \mathrm{cmH}_{2} \mathrm{O}$ and it was close to middle 


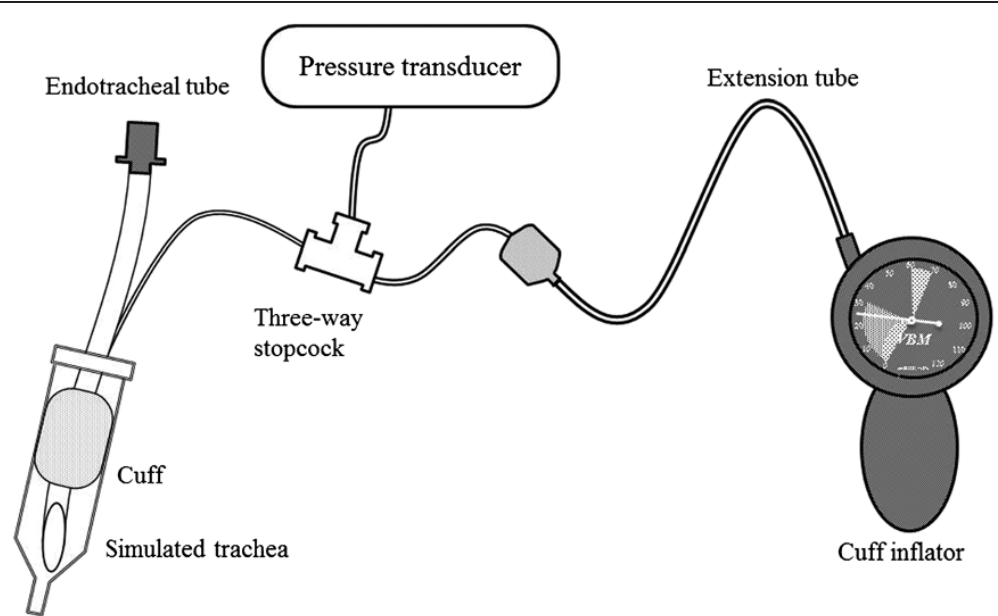

Figure 1 Experimental setup to investigate endotracheal tube cuff pressure changes during measurement procedure. A three-way stopcock was fixed in a pilot cuff line of an endotracheal tube.

of recommended range $\left(20-30 \mathrm{cmH}_{2} \mathrm{O}\right)$. After adjusting the cuff pressure to $24 \mathrm{cmH}_{2} \mathrm{O}$ using a cuff inflator, we waited for equilibrium for about $1 \mathrm{~min}$, disconnected and reconnected the cuff inflator to the inflation valve of the ETT, and calculated the decrease in cuff pressure $\left(\Delta P_{\text {cuff }}\right)$ when reconnecting the cuff inflator. In a preliminary run, by monitoring the cuff pressure continuously, we had confirmed that the cuff pressure was stable for $30 \mathrm{~min}$ without reconnecting the cuff inflator.

We tested three sizes of ETT (internal diameter of 7, 8 , and $9 \mathrm{~mm}$ ) and two cuff shapes-spherical (Blueline, Portex Inc., Keene, NH, USA) and pyriform (TaperGuard Evac, Coviden, Dublin, Ireland) - and both with and without extension tubes, three brands of cuff inflatorCuff Control Inflator, Sofit (both VBM Medizintechnik
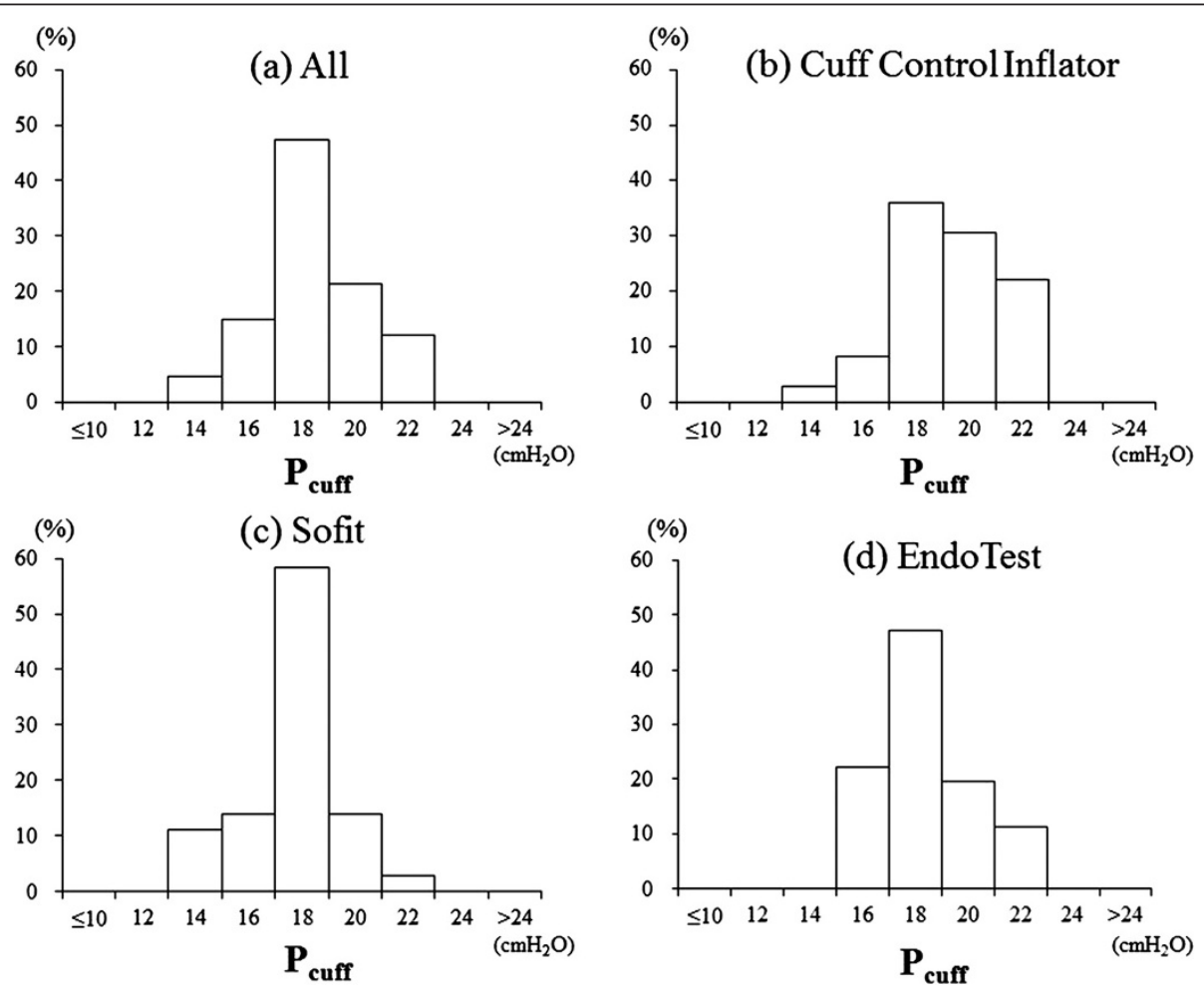

Figure 2 Cuff pressure distribution. (a) All cuff inflators. (b) Cuff Control Inflator. (c) Sofit. (d) EndoTest inflators. Y-axis shows the percentage of all measurements. 


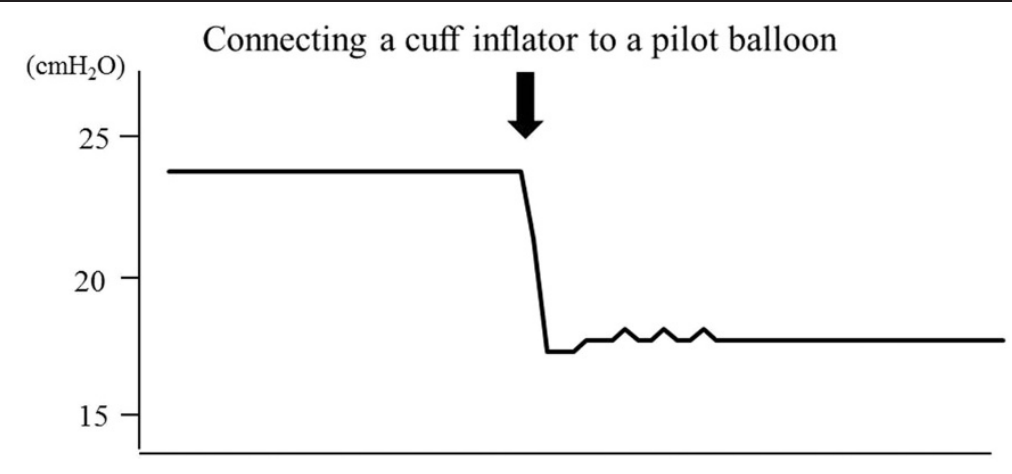

Time

1 second

Figure 3 Representative tracing of cuff pressure during measurement procedure. Cuff pressure decreased during connection of the cuff inflator to the pilot balloon.

GmbH, Sulz am Neckar, Germany), and EndoTest (Rüsch Inc., Duluth, Germany). Because the manufacturer's manual recommended an addition of an extension tube during cuff pressure measurement, we evaluated the effects of the extension tube which was placed between the pilot cuff and the cuff inflator. The same person (SA) repeated the whole test for three times with each combination of ETT size (three kinds), cuff shape (two), and cuff inflator (three), and with or without extension tube (two), resulting in total of 108 measurements. The whole experiment was done in an air-conditioned room $\left(24^{\circ} \mathrm{C}-25^{\circ} \mathrm{C}\right)$ of the intensive care unit at daytime. This study was approved by the ethics committee of the Tokushima University Hospital.

\section{Statistical analysis}

Numerical data are shown as mean \pm standard deviation, when normally distributed. Comparisons of the decrease in cuff pressure were performed with analysis of variance. When significant differences were observed, multiple comparison testing of means was performed using the paired $t$ test with the Bonferroni correction. When not normally distributed, nonparametric tests (Friedman test followed by Wilcoxon signed rank test) were performed. Significance was considered when $p$ value was less than 0.05. Statistical analysis was performed using commercial statistical software (SPSS Inc., Chicago, IL, USA).

\section{Results}

The cuff pressure decreased by $6.6 \pm 1.9 \mathrm{cmH}_{2} \mathrm{O}$ on average with and without extension tubes, when reconnecting the cuff inflator to the pilot balloon. Combining the data from all cuff inflators, the cuff pressure was below 20 $\mathrm{cmH}_{2} \mathrm{O}$ in $67 \%$ of the measurements and always less than $22 \mathrm{cmH}_{2} \mathrm{O}$ (Figure 2a). Three brands of cuff inflators showed similar but different distributions of cuff pressure (Figure 2b,c,d). Figure 3 shows a representative tracing of cuff pressure change.

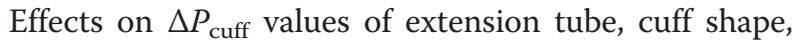
and ETT size are summarized in Table 1 . When an extension tube was present, $\Delta P_{\text {cuff }}$ values were significantly larger than when absent $\left(7.5 \pm 1.9 \mathrm{cmH}_{2} \mathrm{O}\right.$ vs. $5.6 \pm 1.4 \mathrm{cmH}_{2} \mathrm{O}$, $p<0.001)$. There were no significant differences in $\Delta P_{\text {cuff }}$ values among three brands of cuff inflator: Cuff Control Inflator, $7.6 \pm 1.7 \mathrm{cmH}_{2} \mathrm{O}$; Sofit, $7.8 \pm 1.5 \mathrm{cmH}_{2} \mathrm{O}$; and EndoTest, $8.2 \pm 1.4 \mathrm{cmH}_{2} \mathrm{O}(p=0.50)$. The $\Delta P_{\text {cuff }}$ values with pyriform cuffs were significantly larger $(7.9 \pm 1.5$ $\left.\mathrm{cmH}_{2} \mathrm{O}\right)$ than those with spherical cuffs $\left(5.3 \pm 1.3 \mathrm{cmH}_{2} \mathrm{O}\right)$ $(p<0.001$, Figure 4$)$. With different ETT sizes, the $\Delta P_{\text {cuff }}$ values were $9 \mathrm{~mm}, 6.3 \pm 2.0 \mathrm{cmH}_{2} \mathrm{O} ; 8 \mathrm{~mm}, 6.6 \pm 2.1$ $\mathrm{cmH}_{2} \mathrm{O}$; and $7 \mathrm{~mm}, 6.8 \pm 1.6 \mathrm{cmH}_{2} \mathrm{O}$ (Figure 4).

\section{Discussion}

In this study, we found that when reconnecting a cuff inflator to a pilot balloon, the cuff pressure decreased by $6.6 \pm 1.9 \mathrm{cmH}_{2} \mathrm{O}$. This is the first report demonstrating that the procedure for cuff pressure measurement contributes to loss of cuff pressure. The gas pathway within the measuring device needs to have pressure equalization which is proportional to the volume of the pathway. We assume that when connecting the cuff inflator to the pilot balloon, the air compressed inside the cuff escapes into the measurement system, resulting in significant pressure

\begin{tabular}{|c|c|c|c|c|c|c|}
\hline & \multicolumn{3}{|c|}{ With an extension tube } & \multicolumn{3}{|c|}{ Without an extension tube } \\
\hline & $7 \mathrm{~mm}$ & $8 \mathrm{~mm}$ & $9 \mathrm{~mm}$ & $7 \mathrm{~mm}$ & $8 \mathrm{~mm}$ & $9 \mathrm{~mm}$ \\
\hline $\begin{array}{l}\text { Pyriform } \\
\text { shape }\end{array}$ & $8.9 \pm 0.7$ & $9.4 \pm 0.5$ & $9.2 \pm 0.6$ & $6.5 \pm 1.1$ & $6.6 \pm 1.1$ & $6.5 \pm 0.6$ \\
\hline $\begin{array}{l}\text { Spherical } \\
\text { shape }\end{array}$ & $6.2 \pm 1.0$ & $5.9 \pm 1.5$ & $5.6 \pm 0.8$ & $5.4 \pm 1.2$ & $4.4 \pm 0.6$ & $4.1 \pm 1.0$ \\
\hline
\end{tabular}

Mean $\pm \mathrm{SD}\left(\mathrm{cmH}_{2} \mathrm{O}\right)$. The cuff pressure drops are shown for three sizes of endotracheal tubes (internal diameter, 7, 8, and $9 \mathrm{~mm}$ ), with or without an extension tube, and two kinds of cuff shapes (pyriform and spherical). 


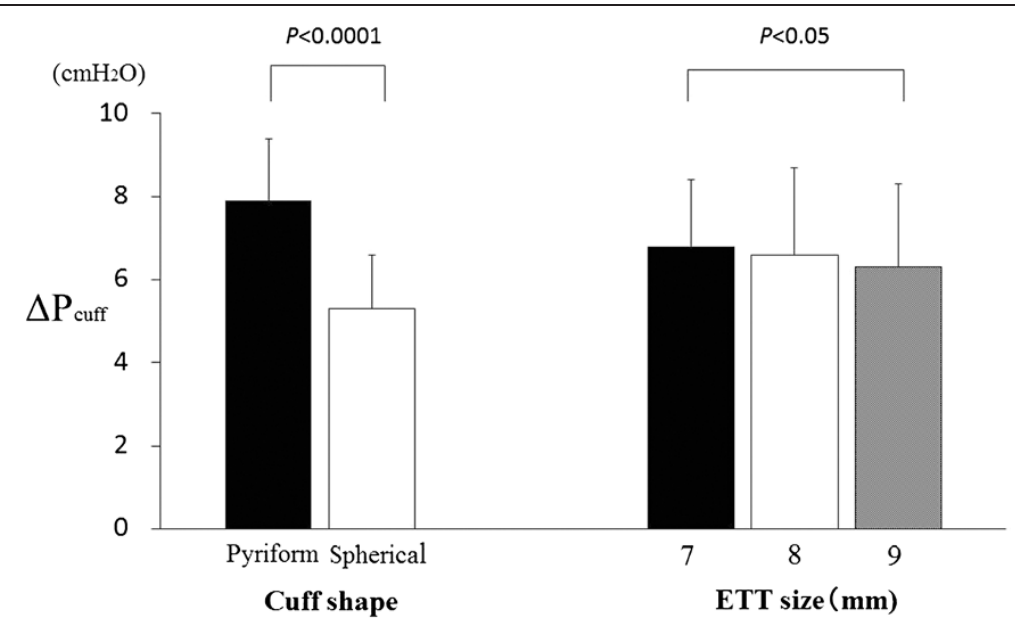

Figure 4 Effects of cuff shape and endotracheal tube size on cuff pressure change during measurement procedure.

loss, because the pressure in the cuff is $24 \mathrm{cmH}_{2} \mathrm{O}$ and the pressure in the cuff inflator and extension tube is 0 $\mathrm{cmH}_{2} \mathrm{O}$. Cuff pressure decreased more when an extension tube was attached. It was likely that the compliance of the measurement system was increased by adding an extension tube, resulting in greater loss of cuff pressure. To avoid these effects, we recommend connecting the cuff inflator directly to the pilot balloon.

Whereas Blanch et al. have reported significant differences among different brands of cuff inflators [7], we found no difference in $\Delta P_{\text {cuff }}$ values among three tested brands of cuff inflator, possibly because the three devices had similar compliance. Blanch et al. speculated that different compressive volumes among the tested cuff inflators resulted in differences in cuff pressure readings. In contrast, prior to this study, we measured the compliance of cuff inflators without an extension tube by injecting the air in $0.5-\mathrm{ml}$ step and found that the compliance was similar (between 0.018 and $0.020 \mathrm{ml} / \mathrm{cmH}_{2} \mathrm{O}$ ). Because the greatest drops in cuff pressure were recorded with a combination of pyriform cuffs and 8-mm size ETT (Table 1), it can be assumed that such configurations have the lowest system volume. Nseir et al. have also reported greater changes in cuff pressure with pyriform cuffs than with standard cuffs [8]. Our findings suggest that $\Delta P_{\text {cuff }}$ depends on cuff shape and volume and that when small-volume cuffs are used, cuff pressure requires more careful control.

This study has several limitations. First, we continuously monitored cuff pressure during measurement procedures only in an experimental setup. Because the syringe used in this study has rigid properties and smaller inner diameter than the trachea, the pressure change may be magnified when compared with a flexible tracheal model. Only the same person (SA) performed the connection/disconnection procedure. Further study is needed to confirm whether similar pressure loss occurs with patients in clinical settings during cyclical mechanical ventilation. Second, we did not investigate long-term changes in cuff pressure or the effects of mechanical ventilation on cuff pressure. Monitoring of long-term changes in cuff pressure may also be important in preventing intubation-related complications. Our results suggest that it may be prudent to use devices that intermittently measure and adjust cuff pressure without extension tubes or continuously adjust cuff pressure.

\section{Conclusion}

The cuff pressure dropped by $6.6 \mathrm{cmH}_{2} \mathrm{O}$ on average when connecting a cuff inflator to an inflation valve of the endotracheal tube. The use of an extension tubing and endotracheal tube with pyriform cuff was associated with larger cuff pressure drop.

\section{Abbreviations}

ETT: endotracheal tube; $\Delta P_{\text {cuff: }}$ decrease in cuff pressure.

\section{Competing interests}

The authors declare that they have no competing interests.

\section{Authors' contributions}

SA established the design of the study, collected the data, and drafted the manuscript. AM, YM, and HK established the design of the study and collected the data. HI assessed the experiment, performed statistical analysis, and revised the manuscript. MN revised the manuscript. All authors read and approved the final manuscript.

\section{Author details}

${ }^{1}$ The University of Tokushima Graduate School, Tokushima 770-0855, Japan. ${ }^{2}$ Emergency and Disaster Medicine, Tokushima University Hospital, Tokushima 770-8503, Japan. ${ }^{3}$ Emergency and Critical Care Medicine, Tokushima University Hospital, Tokushima 770-8503, Japan.

Received: 28 January 2014 Accepted: 14 May 2014

Published: 2 June 2014

\section{References}

1. Sengupta P, Sessler DI, Maglinger P, Wells S, Vogt A, Durrani J, Wadhwa $A$ : Endotracheal tube cuff pressure in three hospitals, and the volume 
required to produce an appropriate cuff pressure. BMC Anesthesiol 2004, 4:8.

2. Sole ML, Su X, Talbert S, Penoyer DA, Kalita S, Jimenez E, Ludy JE, Bennett M: Evaluation of an intervention to maintain endotracheal tube cuff pressure within therapeutic range. Am J Crit Care 2011, 20:109-117.

3. Nseir S, Brisson H, Marquette CH, Chaud P, Di Pompeo C, Diarra M, Durocher A: Variations in endotracheal cuff pressure in intubated critically ill patients: prevalence and risk factors. Eur J Anaesthesiol 2009, 26:229-234

4. Howard WR: Bench study of a new device to display and maintain stable artificial airway cuff pressure. Respir Care 2011, 56:1506-1513.

5. Vyas D, Inweregbu K, Pittard A: Measurement of tracheal tube cuff pressure in critical care. Anaesthesia 2002, 57:275-277.

6. Motoyama A, Asai S, Konami H, Matsumoto Y, Misumi T, Imanaka H, Nishimura M: Changes in endotracheal tube cuff pressure in mechanically ventilated adult patients. I Intensive Care 2014, 2:7.

7. Blanch PB: Laboratory evaluation of 4 brands of endotracheal tube cuff inflator. Respir Care 2004, 49:166-173.

8. Nseir S, Zerimech F, De Jonckheere J, Alves I, Balduyck M, Durocher A Impact of polyurethane on variations in tracheal cuff pressure in critically ill patients: a prospective observational study. Intensive Care Med 2010, 36:1156-1163.

doi:10.1186/2052-0492-2-34

Cite this article as: Asai et al.: Decrease in cuff pressure during the

measurement procedure: an experimental study. Journal of Intensive Care 2014 2:34.

\section{Submit your next manuscript to BioMed Central and take full advantage of:}

- Convenient online submission

- Thorough peer review

- No space constraints or color figure charges

- Immediate publication on acceptance

- Inclusion in PubMed, CAS, Scopus and Google Scholar

- Research which is freely available for redistribution 